\title{
SPATIAL DISTRIBUTION AND INTERSPECIFIC ASSOCIATION PATTERNS BETWEEN SHOREA ROXBURGHII G. DON AND OTHER TREE SPECIES IN A SOUTH VIETNAM EVERGREEN FOREST
}

\author{
QUY, N. V. ${ }^{1,2}-$ KANG, Y. X. ${ }^{1 *}-$ KHOT, ${ }^{1}{ }^{1}-$ HOP, N. V. ${ }^{2,3}-$ TUAN, N. T. ${ }^{2}$ \\ ${ }^{1}$ College of Forestry, Northwest A\&F University, Yangling, Shaanxi 712100, China \\ ${ }^{2}$ Vietnam National University of Forestry - Southern Campus, Trang Bom, Dong Nai 810000, \\ Vietnam \\ ${ }^{3}$ College of Forestry, Fujian A\&F University, Fuzhou, Fujian 350000, China \\ *Corresponding author \\ e-mail:yxkang@nwsuaf.edu.cn; phone:+86-1522-930-8798
}

(Received $30^{\text {th }}$ Jun 2021; accepted 20 th $\operatorname{Sep} 2021$ )

\begin{abstract}
To understand the ecology and spatial distribution patterns of Shorea roxburghii, a vulnerable plant on the IUCN's Red List, this study was conducted in a Vietnamese evergreen forest. To collect data, a $100 \mathrm{~m} \times 100 \mathrm{~m}$ plot was established in the Tan Phu protected forest, in South Vietnam. Relative density, relative basal area, and importance value index (IVI) were determined for each species. Individuals were categorized by juvenile $(\mathrm{dbh}<5 \mathrm{~cm})$, subadult $(5 \mathrm{~cm} \leq \mathrm{dbh}<10 \mathrm{~cm})$ and adult $(\mathrm{dbh} \geq 10 \mathrm{~cm})$ life-history stages. We used Excel, Programita Noviembre 2018 and R to analyze data. Spatial analyses focused on overall univariate patterns, dispersion patterns, and hetero-specific association of the species. A total of 111 species was found. Shorea roxburghii has higher basal area, relative density, maximum dbh, IVI and lower median main neighbour. Shorea roxburghii has cluster distribution in the juvenile (5f) and subadult stage $(5 \mathrm{~g})$, regular or clustered pattern in the adult stage $(5 \mathrm{~h})$. However, the general trend is a regular pattern as the dbh increases. With the achieved results, this study contributes to the simulation method of forest species ecological characteristics, including distribution characteristics, intra and interspecific relationships in the space of Shorea roxburghii.
\end{abstract}

Keywords: threatened species, life-history stages, ecological characteristics, interspecific relationships, conservation planning

\section{Introduction}

Biodiversity management lies on the master of many ecological rules and mechanisms from local and global environmental and biotic variables. To efficiently manage and conserve wild resources, the understanding of their ecology, biology and behaviour is crucial (Cirimwami et al., 2019). Plant species communities are under the effect of deterministic factors albeit some stochastic forces cannot be ruled out (Amani and Lejoly, 2014). Fine-scale study of population successional dynamic, natural and human-driven threats acting on forest ecosystems, spatial distribution patterns... could also be important to efficiently manage plant resources worldwide (Getzin et al., 2006). The studies aiming at the understanding of spatial distribution patterns of tree species are very essential because these studies allow us to understand mechanisms of plant species competition and coexistence (Getzin et al., 2006; Guo et al., 2013), plant species diversity (Fibich et al., 2016), successional dynamics of species (Arévalo and Fernández-Palacios, 2003; Wédjangon et al., 2020), forest structure and composition change (Call et Nilsen, 2003) as well as species intraspecific and interspecific association patterns (Wédjangon et al., 2020). 
To understand these floristic parameters is important, for example, the competition is one of major ecological processes regulating forest communities (Nguyen et al., 2020a).

Shorea are a tropical genus counting approximately 196 species, most of them belonging to rainforest ecosystems. More than $75 \%$ of Shorea species (about 148 species) are present on the plant species Red List of IUCN; the majority of them are critically endangered. Despite this situation, many Shorea species are economically important timber trees (Raju et al., 2009). Shorea roxburghii G. Don (from the Dipterocarpaceae family) is classified as "Vulnerable" on the IUCN Red List due to many threats to which it is subjected. This species is found in the mixed dipterocarp forests in countries such as Cambodia, India, Lao Popular Democratic Republic, Peninsular Malaysia, Myanmar, Thailand and Viet Nam (Pooma et al., 2017). The species has an economic significance as it is used as valuable commercial timber and as 'white meranti' in many countries of the Southeastern Asia region. A population reduction of at least $30 \%$ in the last three centuries has resulted in overall population decline and potential future species decline. This being a consequence of agriculture practices and timber logging, these are the principal threats to the species $S$. roxburghii (Pooma et al., 2017; Mun et al., 2018).

The germination of $S$. roxburghii is not easy. In an experimental plot where many seeds were sown, Raju et al. (2011) obtained $8 \%$ of seed germination rate which also explains and increases the vulnerability of the species. By this difficulty in its germination, the plant could encounter a disequilibrium in its population structure, having many more mature individuals than sapling ones. Its adult trees may reach about $28 \mathrm{~m}$ in height. Although this species has a low rate of seed germination (Raju et al., 2011), seeds which succeed to germinate are supposed to have a high survival rate (Mun et al., 2018).

The species $S$. roxburghii is a fast-growing species (Mun, 2018). In good conditions, the adult individual of the species (six-year-old $S$. roxburghii with dbh and height of $23.6 \mathrm{~cm}$ and $16.6 \mathrm{~m}$ ) achieve $4 \mathrm{~cm}$ per year for dbh and $3 \mathrm{~m}$ per year for height (Mun, 2018; Nguyen et al., 2020c). Being a semi-evergreen tree species, $S$. roxburghii is a brief leafless species especially during the dry season. $S$. roxburghii is usually found in combination with other species from Dipterocarpaceae, Myrtaceae and Euphorbiaceae families (Raju et al., 2011).

Assessments on the ecology and living strategies of a rare or an important species, is a way for managers, conservationists as well as planners to protect the species from many threats (Pham et al., 2020). Thus, understanding the spatial structure and association of this species Shorea roxburghii in its different life-history stages could help in the explanation of its ecology and population dynamics in the studied area as it was the case for other species from the northern evergreen forests of Vietnam (Nguyen et al., 2014, 2020a). The management of $S$. roxburghii in local forests and areas where it is located suggests the understanding of its ecology including the study of its population structure, dendrometric characteristics, the spatial distribution patterns and interspecific association patterns with its closer neighbours. The principal objective of this paper is to contribute to the improvement of the conservation status of $S$. roxburghii trees in South Vietnam evergreen forests. Four (4) main questions will be addressed: i) How are the population structure and dendrometric characteristics (Stem density, diameter, and importance value index) of Shorea roxburghii compared to its neighbours? ii) What are the spatial distribution patterns from juvenile stage to adult stage of $S$. roxburghii? iii) How does $S$. roxburghii coexist with its main neighbours tree species when comparing their spatial distribution patterns? iv) How do these interspecific association patterns change with life stages? 


\section{Material and methods}

\section{Study area}

This research study was conducted at Tan Phu protected forest, Dong Nai province, Southern Vietnam (11 ${ }^{\circ} 7^{\prime} 36^{\prime \prime} \mathrm{N}$ of latitude and $107^{\circ} 24^{\prime} 46^{\prime \prime} \mathrm{E}$ of longitude). Tan Phu protected forest is a tropical moist evergreen forest, which covers 13733.12 ha, in which forested land accounts for 89.76\% (12 127.41 ha) of the total area (Fig. 1). This area has been reported as a species-rich ecosystem with many highly valuable plant species. The Tan Phu protected forest has a major economic role as it participates in the storing of carbon, the nourishing and protection of soil, and the water resources for Tri An hydroelectricity reservoir in the Dong Nai province. The average elevation of this area ranges from 60 to $120 \mathrm{~m}$ a.s.1. The annual mean temperature of the study area is $27.1{ }^{\circ} \mathrm{C}$, while the annual mean humidity is $82 \%$ and the average annual rainfall is $2.140 \mathrm{~mm}$ year $^{-1}$ (Nguyen et al., 2020b). This forest ecosystem was specifically selected to conduct the present study on the spatial distribution of Shorea roxburghii. The study was carried out from December 2020 to April 2021 with four field surveys at Tan Phu Protection Forest.

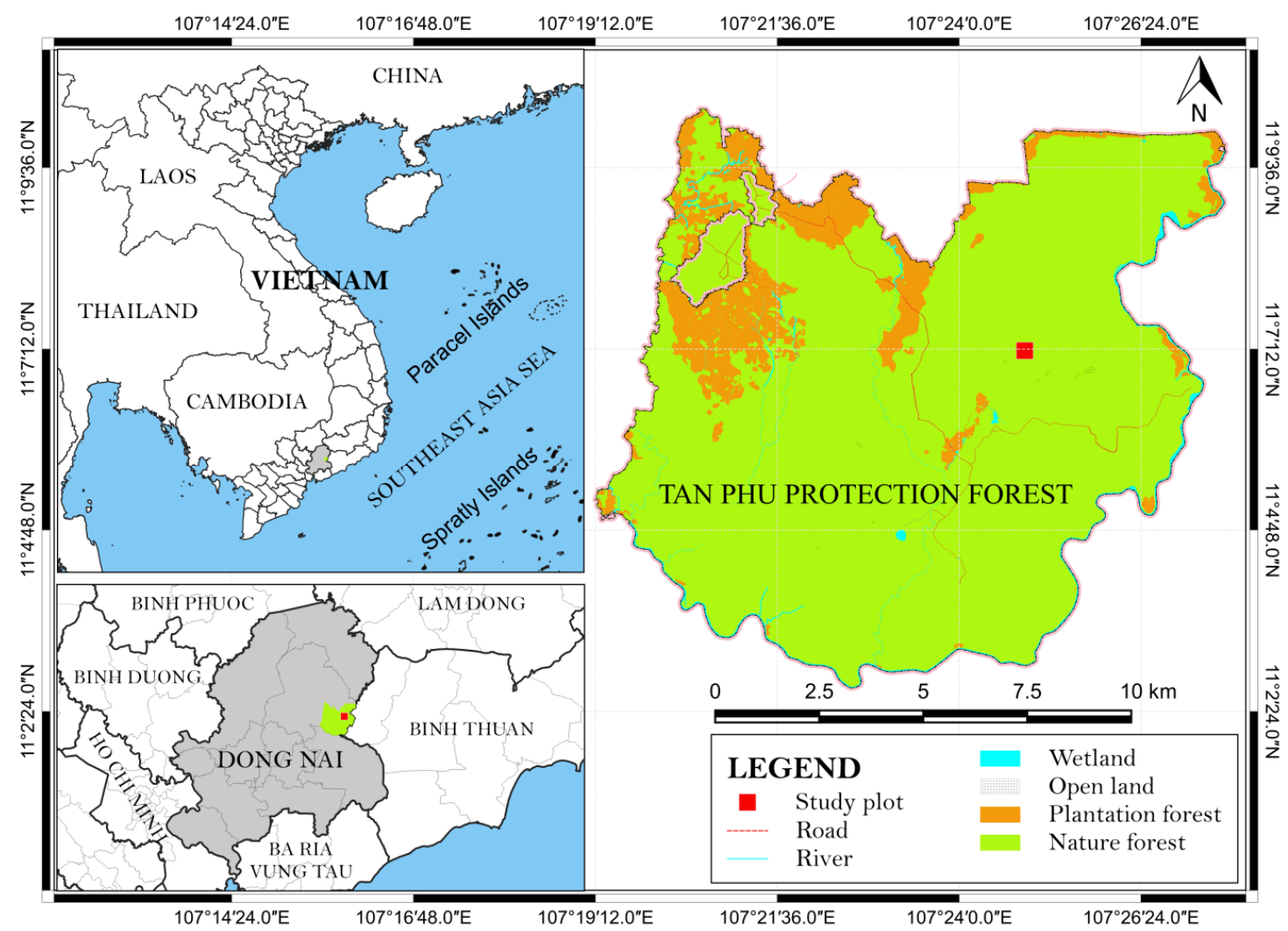

Figure 1. Map of the study area

\section{Data collection}

We selected a stand where Shorea roxburghii species distributed and predominated to establish the 1 ha $(100 \mathrm{~m} \times 100 \mathrm{~m})$ study plot in the Tan Phu forest $\left(11^{\circ} 7^{\prime} 7.97^{\prime \prime} \mathrm{N}\right.$ of latitude and $107^{\circ} 24^{\prime} 56.31^{\prime \prime} \mathrm{E}$ of longitude). This plot continues to be broken down into 
100 subplots $(10 \mathrm{~m} \times 10 \mathrm{~m})$ to facilitate the investigation, avoiding the omission of tree species. All woody plants with dbh (diameter at breast height) $>2.5 \mathrm{~cm}$ were tapped, numbered, tapped and measured in each plot. A wooden stick $1.3 \mathrm{~m}$ in length will be used to identify the location of $1.3 \mathrm{~m}$, which will avoid mistakes regarding the correct measuring height. Moreover, climbers, vines, and loose bark must be removed before measuring to avoid mistakes in the measured process. The coordinates of all plots were marked by GPS meter.

All individual trees were allocated into one of the three basic life-history stages, namely, juvenile $(\mathrm{dbh}<5 \mathrm{~cm})$, subadult $(5 \mathrm{~cm} \leq \mathrm{dbh}<10 \mathrm{~cm})$, or adult $(\mathrm{dbh} \geq 10 \mathrm{~cm})$. The identification of trees was done in the field during plot inventory. When some species were not identified in the field, voucher specimens were collected, prepared and subsequently identified by taxonomic specialists after the field work.

\section{Data analysis}

Different parameters were calculated as below:

$$
\mathbf{d}=\frac{\mathrm{n}_{1}}{\mathrm{~s}}
$$

where $d$ is the stem density of species $i$ (the number of individual trees ha ${ }^{-1}$ ), $n_{i}$ is the total individual trees calculated for species $\mathrm{i}$ (the number of individual trees) and $\mathrm{S}$ is the study plot area (unit of area in ha) (Brower et al., 1997).

$$
\mathbf{B A}=\pi \times \mathbf{r}^{2}=\frac{3.142 \times \mathrm{dbh}^{2}}{200^{2}}
$$

where BA is the tree basal area $\left(\mathrm{m}^{2}\right), \mathrm{r}$ is the radius and $\mathrm{dbh}$ is the diameter at breast height $(\mathrm{cm})$ (Brower et al., 1997)

$$
\operatorname{IVI}(\%)=\frac{\mathbb{R D}+\operatorname{REA}}{2}
$$

where RD is the relative density and RBA is the relative basal area. The relative basal area is defined as total basal area of species $i$ as a percent of the total basal area of all species. The ecological value of species in a forest stand is obtained by determining its importance value index (Curtis and Macintosh, 1951).

The data was analysed by using Excel 2013, Programita Noviembre 2018 and R 4.0.5 software. Excel was used to present the population structure and dendrometric characteristics. Point pattern analyses were performed using the Programita software (Wiegand and Moloney, 2004). The spatstat package implemented in R software was used for spatial distribution and interspecific association patterns (Baddeley et al., 2015). We used the spatstat package to make the distribution map of all species in the studied area, the pair-correlation function, Ripley's K functions, and L-function as it is explained by many researchers over the world (Dixon, 2002; Sotirios and Alan, 2005; Getzin et al., 2006; Bolibok, 2008; Nguyen, 2017; Wédjangon et al., 2020; Nguyen et al., 2021).

The Ripley's K-function is the expected number of points in the $r$ distance of an arbitrary point which is divided by the intensity $\lambda$ where $\lambda$ is the intensity of the pattern in the study area (Ripley, 1976). According to the tree-tree distances, $\mathbf{g}_{11}(\mathbf{r})$ (univariate 
pair-correlation function) describes the spatial distribution of trees at $\mathrm{r}$ radius using a standardized density. Consequently, when this parameter equals to 1 it means under complete spatial randomness, $>1$ indicates aggregation and $<1$ indicates regularity at distance $\mathrm{r}$ within trees of the pattern. The parameter $\mathrm{g}_{12}(\mathrm{r})$ (bivariate pair-correlation function) was used to describe spatial association between two types of points. Function $\mathrm{g}_{12}(\mathrm{r})_{\text {is }}$ the expected density of points of type 2 at $\mathrm{r}$ distance beginning from a randomly chosen point of type 1 . Similarly to the univariate version, $\mathbf{g}_{\mathbf{1 2}}(\mathrm{r})=1$ indicates independence, $\mathrm{g}_{12}(\mathrm{r})<1$ indicates repulsion and $\mathrm{g}_{12}(\mathrm{r})>1$ indicates attraction between two tree species at distance $r$ (Nguyen et al., 2014).

Null models of random distribution, spatial independence and random labelling of trees were tested for null hypotheses related to ecological questions (Goreaud and Pelissier, 2003; Wiegand and Moloney, 2004; Illian et al., 2008). As it was done by other authors, the significant departure from the null models was evaluated using 999 Monte Carlo simulations. Approximately 99\% confidence envelopes were built by 5 th lowest and highest values of these simulations. Point pattern analyses were performed using the software Programita (Wiegand and Moloney, 2004). We used the null model complete spatial randomness to investigate whether the environmental heterogeneity restricted spatially the tree distribution based on the spatial distribution of all adult trees. The distribution of all adult trees at scales beyond direct tree-tree interaction should indicate environmental suitability for colonization and growth as well as allow capturing of environmental effects common to all species within the stand (Getzin et al., 2008). L-function and pair-correlation function allowed us to observe the change in tree density from both cumulative and non-cumulative perspectives at various scales. As mentioned by Wiegand et al. (2007), in plant communities, clumping at small scales generally indicated plant-plant interactions, while at large scales it showed the effect of environmental heterogeneity.

\section{Analysis 1: Overall univariate patterns}

The spatial distributions in size classes of all species, $S$. roxburghii and the remaining species were analyzed and compared using the univariate pair-correlation function. We tested the null hypothesis of a random univariate spatial distribution of trees in each life-history stage (juvenile, subadult and adult). If a random distribution of a life stage over the entire plot was confirmed, this meant that no strong interaction occurred between the trees within this size class. Comparisons of the spatial distributions of the whole plot with and without considering $S$. roxburghii allowed us to interpret the abundance effect of the species. Overall, we expected that spatial patterns of adult trees were more regular than those of earlier life-history stages, with the increase of tree size being evidence of self-thinning.

\section{Analysis 2: Dispersion patterns of S. roxburghii}

Using random labelling null model, we investigated whether or not a random structure of two labels occurred within the joined patterns. The g-functions are invariant under random thinning of the joined patterns 1 and 2 (Wiegand and Moloney, 2004). Thus, we expected $g_{12}(r)=g_{21}(r)=g_{11}(r)=g_{22}(r)$. In our case-control design, control was pattern 1 (adult trees) and case was pattern 2 (one of the early life-history stages). If the test statistic $g_{12}(r)-g_{11}(r) \approx 0$, it meant that individuals of pattern 2 
around individuals of pattern 1 at scale $r$ were distributed in the same way as individuals of pattern 1 around themselves. Therefore, this would imply that both life-history stages exploit the natural resources at that scale in a similar way (Getzin et al., 2008). In addition, if the test statistic $\mathbf{g}_{21}(\mathrm{r})-\mathbf{g}_{22}(\mathrm{r})<<0$, there were more individuals of cases than controls in proximity of case individuals, therefore we would expect an additional clustered pattern of cases independent of the controls (i.e. adult trees).

We used a case-control design to estimate mutual effects between early life-history stages (cases) and the adult stage (control) of $S$. roxburghii. Under the null hypothesis of random labelling, if the cases did not show any significant difference from the controls then they were a random subset of the joint pattern of both cases and controls. We expected a clustering of the cases reflecting regeneration mechanisms via independent clumping relative to the controls and, if clustering decreased with increasing size class, density-dependent thinning with increasing size class. For example, there may be an additional clustering of juveniles independently from adult trees that may be caused by canopy gaps with conditions suitable for survival and growth of juveniles. Details on spatial patterns statistics were developed and used by many authors (Bivand et al., 2008; Illian et al., 2008; Macron, 2010; Szmyt, 2014; Baddeley et al., 2015).

\section{Analysis 3: Hetero-specific association of S. roxburghii}

To describe the spatial association between adult trees of the remaining species (pattern 1) and the different life-history stages of S. roxburghii (pattern 2), we used the bivariate pair-correlation function. The null hypothesis of spatial independence was used to test for non- randomness in spatial arrangement between two patterns based on the assumption that the two patterns were generated by two independent processes. We kept the first pattern unchanged and then randomly shifted the second pattern relative to pattern 1 (Wiegand and Moloney, 2004). We hypothesized that $S$. roxburghii had gap-phase regeneration mode, i.e. the early stages of $S$. roxburghii were clustered independently of con-specific adults and simultaneously, they were repulsed by hetero-specific adults. Thus, we expected a negative association of pattern 2 (a life-history stage of $S$. roxburghii) relative to pattern 1 (adult trees of the remaining species).

\section{Results}

\section{Dendrometric characteristics}

In Table 1 we compare Shorea roxburghii's IVI (importance value index), stem density and basal area with its main local neighbours' tree species viz. Aporosa planchoniana, Syzygium zeylanicum, Vatica odorata and Anisoptera costata.

A total of 1371 individuals with $\mathrm{dbh} \geq 2.5 \mathrm{~cm}$ were enumerated in the 1-ha study plot, 111 species were identified and belonged to 43 families while one species was not fully identified (Lauraceae). Shorea roxburghii (Dipterocarpaceae) was most abundant with 271 individuals ha ${ }^{-1}$ (Table 1), approximately $19.8 \%$ of the total. The four most abundant species following Shorea roxburghii species were Aporosa planchoniana (Phyllanthaceae), Syzygium zeylanicum (Myrtaceae), Vatica odorata (Dipterocarpaceae) and Anisoptera costata (Dipterocarpaceae), with respectively 117, 91, 62 and 61 trees ha ${ }^{-1}$. The species Shorea roxburghii and its four main neighbours 
(Aporosa planchoniana, Syzygium zeylanicum, Vatica odorata and Anisoptera costata) account for 602 stems $^{-1}$ in the studied area. S. roxburghii has more stems per ha than these four aforementioned species $(\chi=253.28, \mathrm{df}=4$, $\mathrm{p}$-value $<0.0001)$. This species has the higher value of total basal area, maximum dbh, important value index and lower median NN when compared to four main species in the study plot. When compared to the remaining species, the maximum dbh of Shorea roxburghii is too small (69.4 vs 106.6).

Table 1. Dendrometric characteristics of Shorea roxburghii and its main neighbours tree species

\begin{tabular}{c|c|c|c|c|c|c}
\hline Species & $\begin{array}{c}\text { Stem density } \\
\left(\mathbf{h a}^{-\mathbf{1}} \mathbf{)}\right.\end{array}$ & $\begin{array}{c}\text { Basal area } \\
\left(\mathbf{m}^{\mathbf{2}} \mathbf{h a}^{-\mathbf{1}} \mathbf{)}\right.\end{array}$ & $\begin{array}{c}\text { Average } \\
\mathbf{d b h} \mathbf{( c m )}\end{array}$ & $\begin{array}{c}\text { Maximum } \\
\mathbf{d b h} \mathbf{( c m})\end{array}$ & $\begin{array}{c}\text { Median } \\
\mathbf{N N}(\mathbf{m})\end{array}$ & $\begin{array}{c}\text { Importance } \\
\text { value index (\%) }\end{array}$ \\
\hline Shorea roxburghii & 271 & 12.24 & $17.74 \pm 16.17$ & 69.4 & 2.93 & 29.48 \\
Aporosa planchoniana & 117 & 0.58 & $6.77 \pm 4.22$ & 39.5 & 4.82 & 5.20 \\
Syzygium zeylanicum & 91 & 1.76 & $12.59 \pm 9.43$ & 50.9 & 5.33 & 6.14 \\
Vatica odorata & 62 & 0.76 & $10.61 \pm 6.71$ & 39.5 & 6.19 & 3.48 \\
Anisoptera costata & 61 & 2.61 & $18.93 \pm 13.79$ & 53.5 & 6.03 & 6.40 \\
Others (106 species) & 769 & 13.26 & $10.58 \pm 10.39$ & 106.6 & 1.84 & 49.29 \\
All & 1371 & 31.21 & $12.17 \pm 11.92$ & 106.6 & 1.39 & 100 \\
\hline
\end{tabular}

$\mathrm{dbh}$ : diameter at breast height; $\mathrm{NN}$ : nearest neighbour distance

\section{Diameter class distribution}

The comparison of diameter classes between Shorea roxburghii and the four neighbours species (Aporosa planchoniana, Syzygium zeylanicum, Vatica odorata and Anisoptera costata) as well as other remaining species (Fig. 2).
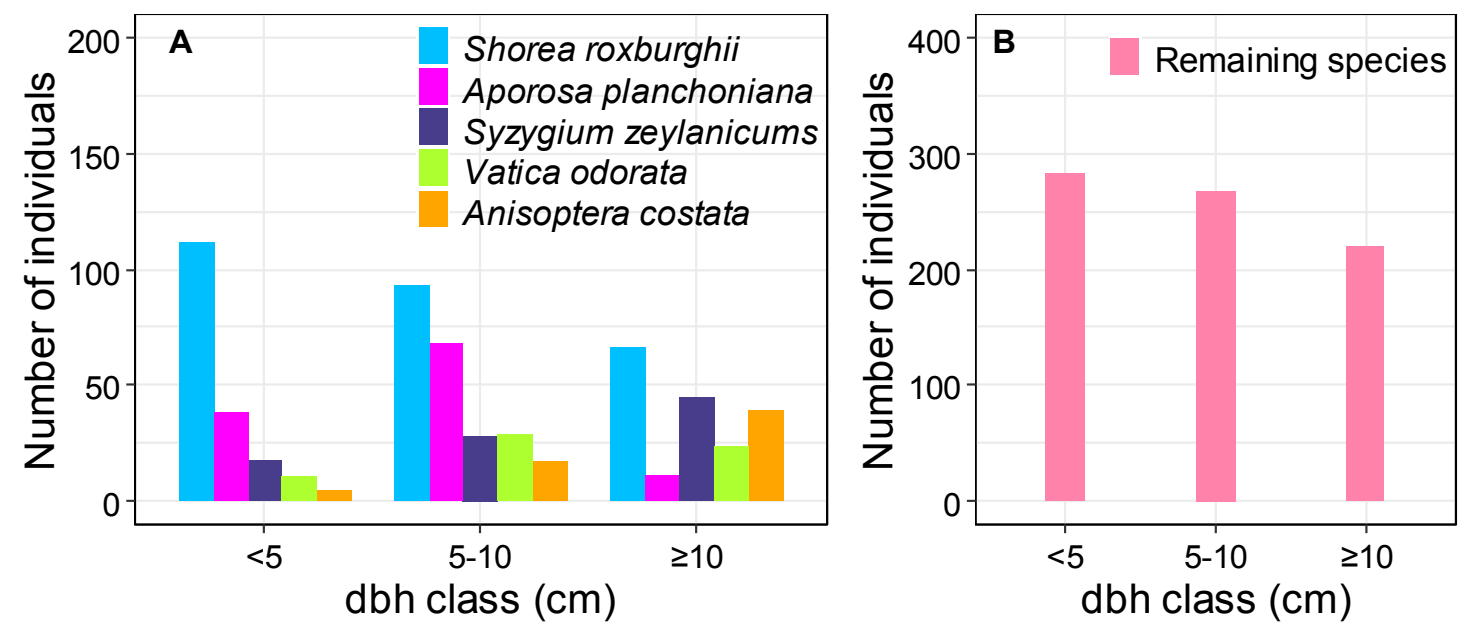

Figure 2. Dbh class distribution of Shorea roxburghii and its main neighbours (A) and the remaining species (106 species) in the study plot (B)

As shown in Figure 2, when compared to four main species in the study plot, Shorea roxburghii has more individuals than other species in any diameter class from juvenile 
tree class $(\mathrm{dbh}<5 \mathrm{~cm})$ to adult tree class $(\mathrm{dbh} \geq 10 \mathrm{~cm})$. In general, classes with many individuals are juvenile and subadult tree classes $(5 \mathrm{~cm} \leq \mathrm{dbh}<10 \mathrm{~cm})$. This trend is also shaped by Shorea roxburghii with the number of juvenile and subadult individuals accounting for $75.6 \%$ of the total number of individuals of species. The dbh distribution characteristics showed that the forest status here is not stable. There will be changes at a future stage when the number of trees at small diameter classes is large.

\section{Spatial patterns}

\section{Univariate patterns for all species}

In Figure 3, we present the distribution map of all tree individuals according to their spatial patterns.

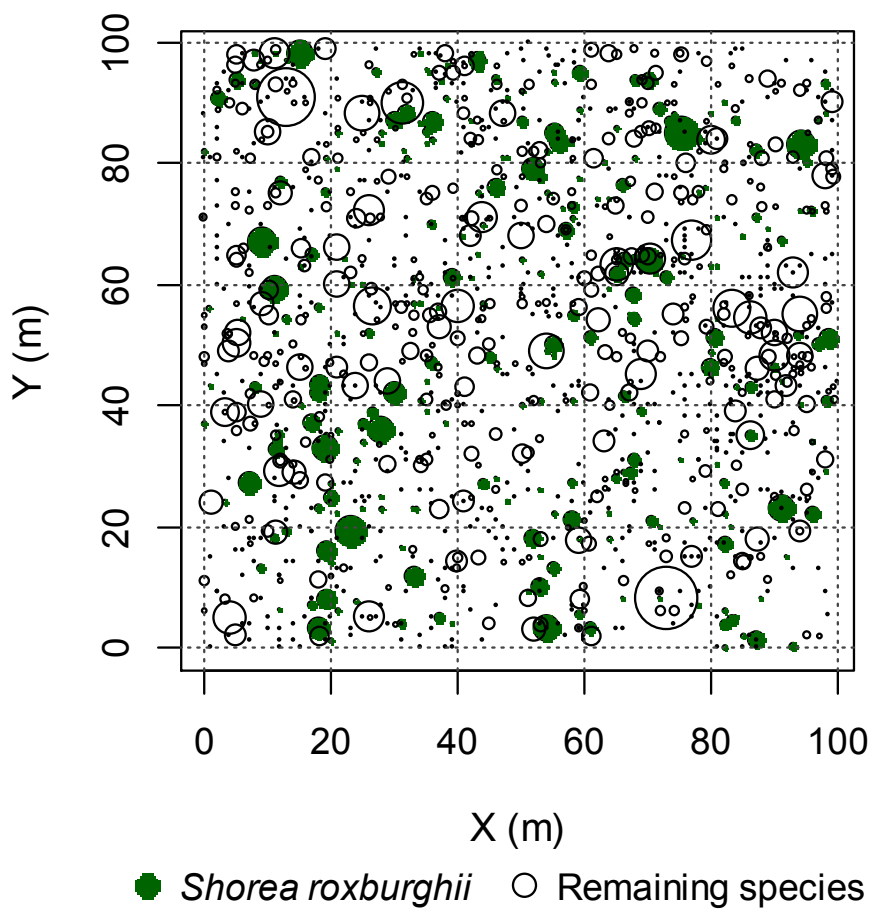

Figure 3. Individuals' distribution map: Shorea roxburghii (darkgreen circles) and the remaining species (open circles). The size of symbols is related to the dbh of the individual

The pattern drawn in Figure 3 illustrates that in general case when considering all the collected species, Shorea roxburghii species do not have many bigger trees (in terms of the diameter at breast height: dbh) compared to other remaining species. The dbh stretches between $2.5 \mathrm{~cm}$ to $106.6 \mathrm{~cm}$. However, the species Shorea roxburghii does not have very smaller individuals (according to its dbh sizes: radius of circles in Fig. 3) compared to the remaining species (110 species).

Figure 4 presents the univariate L-function (on the left) and pair-correlation function (on the right) for spatial distribution for all adult trees $(\mathrm{dbh} \geq 10 \mathrm{~cm}$ ). In the light of Figure $4 a$, according to the L-function, the drawn pattern is regular at low scale between 0 and $5 \mathrm{~m}$ and it becomes a clustered pattern as long as the scale increases (from $22 \mathrm{~m}$ and above). These patterns are shaped for all the species and individuals with $\geq 10 \mathrm{~cm}$ dbh. When considering Figure $4 b$ (pair-correlation function), spatial 
pattern for all adult trees was regular distribution at scales up $2 \mathrm{~m}$, and cluster distribution at a distance of 9-10 m, 12-13 m, 20-23 m.

(a) All adults

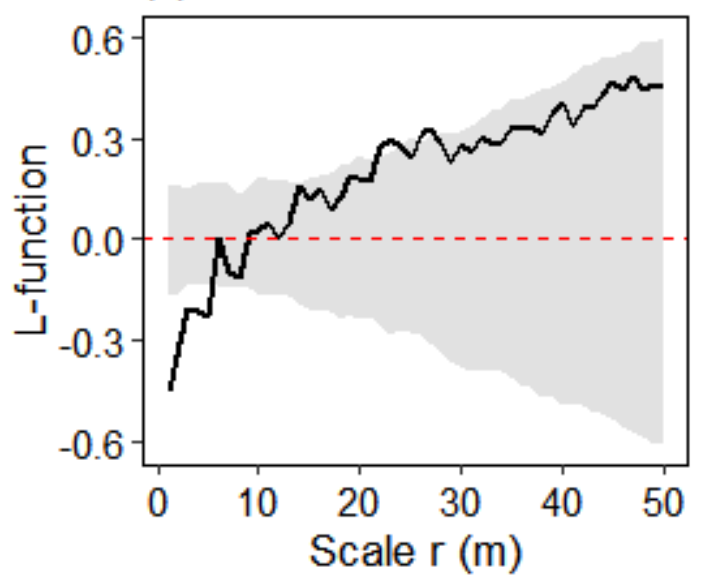

(b) All adults

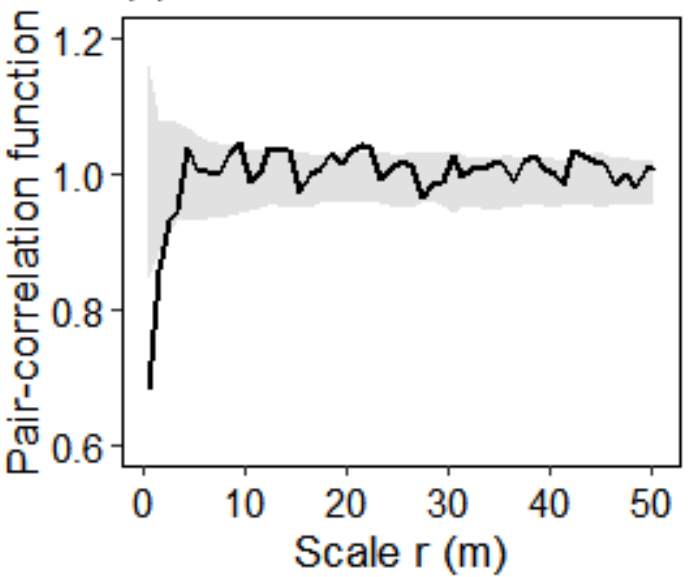

Figure 4. Univariate L-function and pair-correlation function show spatial distributions of all adult trees $(\mathrm{dbh} \geq 10 \mathrm{~cm})$ at different scales. Dark line lying beyond the confidence envelope region (grey area) indicate significant departure from the null model of complete spatial randomness. The grey envelope region are the $p=0.05$ confidence interval for Monte Carlo simulations around the red 0 dashed straight line (values $<0$ indicate a regular pattern; values $>0$ a clustered pattern)

\section{Variation of spatial distribution patterns considering all life stages}

The spatial distribution patterns for juveniles, subadults and adults individuals are shown in Figure 5. From Figure $5 a$ to $d$ we present all species, from Figure $5 e$ to $h$ we present the spatial distribution patterns shaped by Shorea roxburghii at its all life stages and from Figure $5 i$ to $5 l$ we represent the remaining species excluding $S$. roxburghii.

From Figure $5 b-d$, we noticed that concerning all species combined together, the spatial patterns of juveniles, subadults and adults passed from aggregation structure to regular pattern with the increasing of tree sizes from juveniles to adults. When gathered (juveniles + subadults + adults) in Figure $5 a$, regular patterns of all trees at scales up to $2 \mathrm{~m}$ is shaped. On one hand, the cluster distribution at a juveniles stage and subadults is partly due to the size of a small tree, thus competition between trees is not clear. On the other hand, the environment in the study plot is heterogeneous through the testing of $g$ and $\mathrm{L}$ functions. When considering only the case of Shorea roxburghii species, the juveniles + subadults + adults of this species showed a general clustered spatial distribution pattern at scales up to $26 \mathrm{~m}$ (Fig. 5e). Shorea roxburghii has cluster distribution type in the juvenile (Fig. 5f) and subadult stage (Fig. 5g), regular pattern or clustered pattern in the adults stage (Fig. 5h). However, the general trend is regular pattern as the dbh of trees increases. Spatial distribution of all Shorea roxburghii tree (Fig. 5e) shows that it has cluster distribution at the distance up to $25 \mathrm{~m}$. This is explained by its strong particle dispersion ability. Considering the ecological characteristics, the Shorea roxburghii tree has a winged fruit, this is an advantage in dispersing. There is no competition at the juveniles stage (Fig. 5f) and the subadults (Fig. 5g), but there is competition in the adults with a scales of $0-5 \mathrm{~m}$ (Fig. 5h). 
(a) All trees

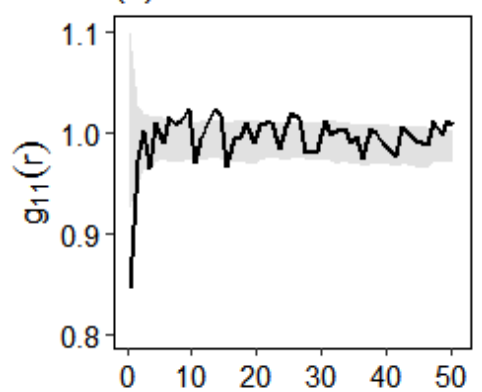

(b) All juveniles

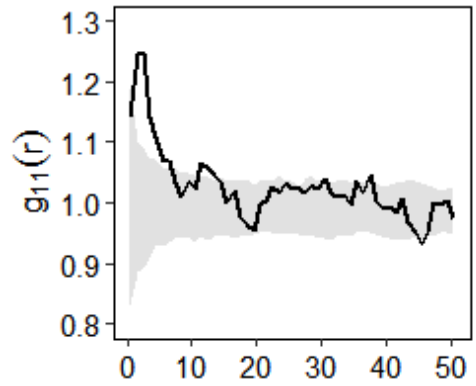

(c) All subadults

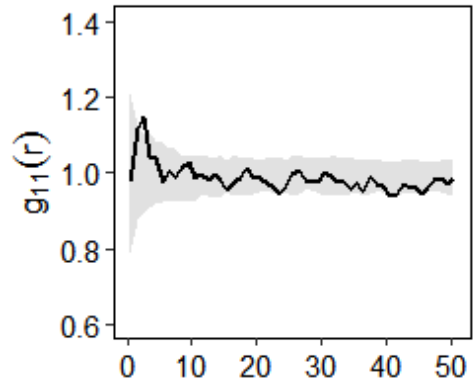

(d) All adults

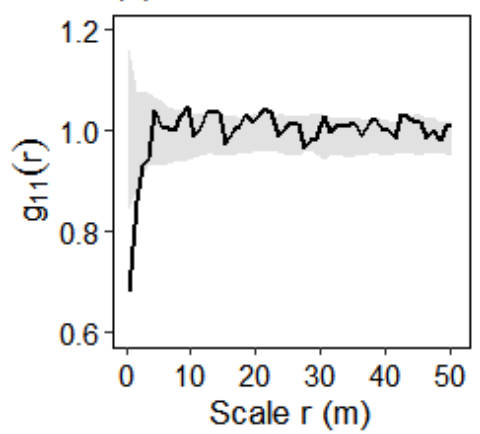

(e) Shorea roxburghii

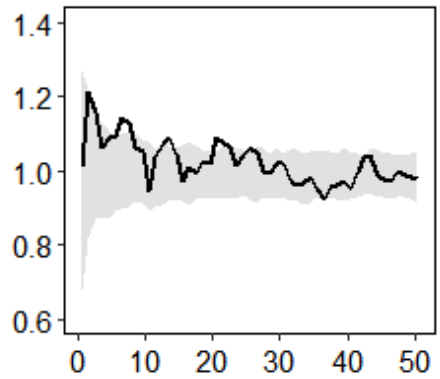

(f) $S$. roxburghii juveniles

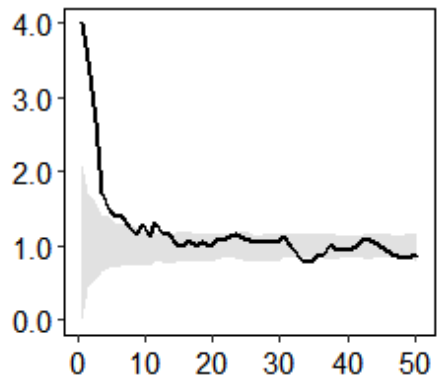

(g) $S$. roxburghii subadults

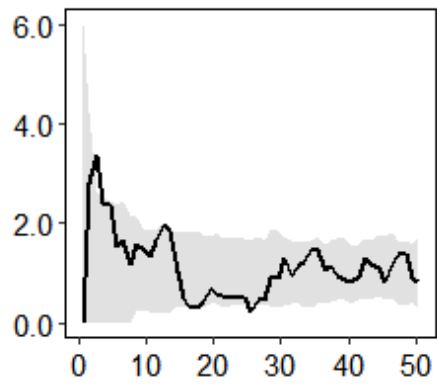

(h) S. roxburghii adults

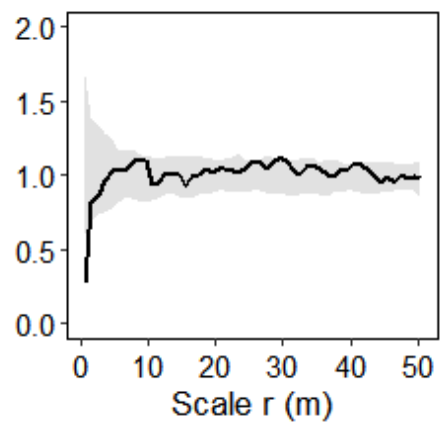

(i) Remaining species

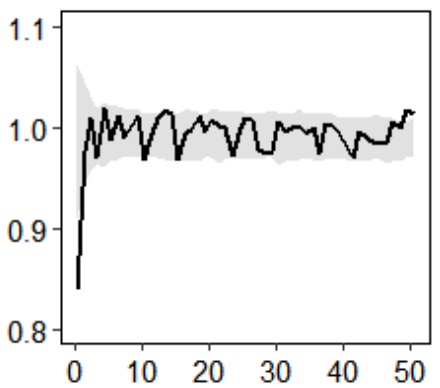

(k) Remaining juveniles

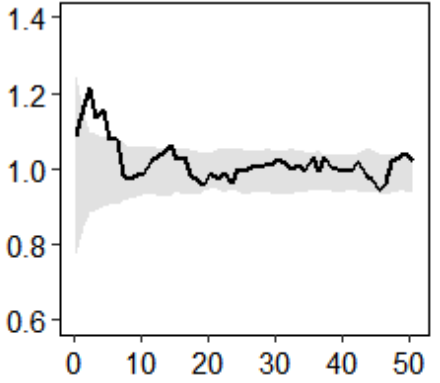

(I) Remaining subadults

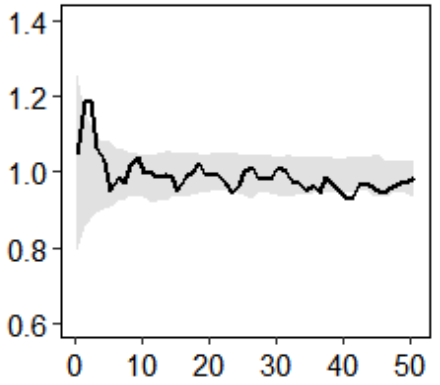

(m) Remaining adults

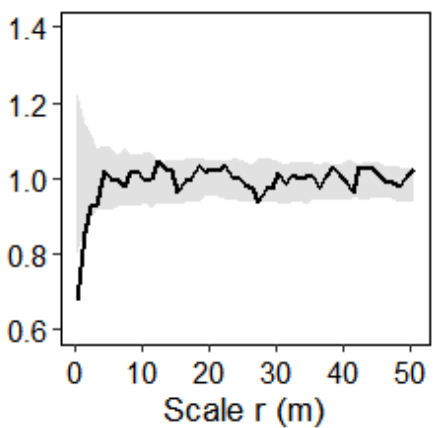

Figure 5. Spatial distributions of all individuals and life-history stages of all species $(a-d)$, Shorea roxburghii $(e-h)$ and remaining species $(i-l)$ are shown by the univariate paircorrelation function $\mathrm{g}_{11}(\mathrm{r})$

\section{Dispersion patterns of the studied species Shorea roxburghii}

In Figure 6 we compare the spatial distribution patterns of adults and earlier life stages (juveniles and subadults) of the species Shorea roxburghii in the study area. 
(a) Adults vs. juveniles

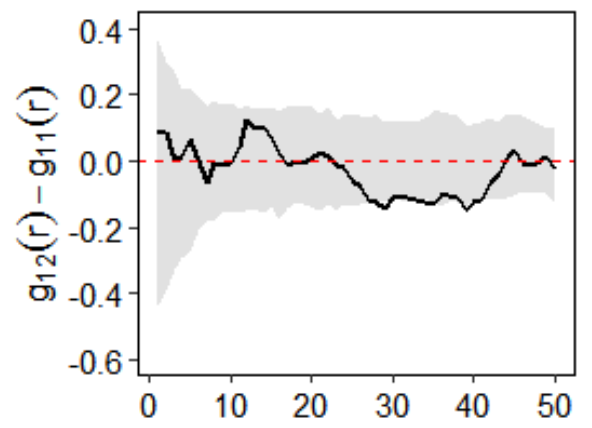

(c) Adults vs. juveniles

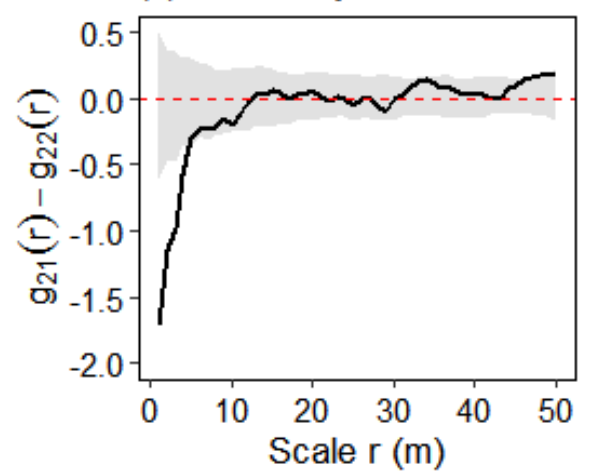

(b) Adults vs. subadults

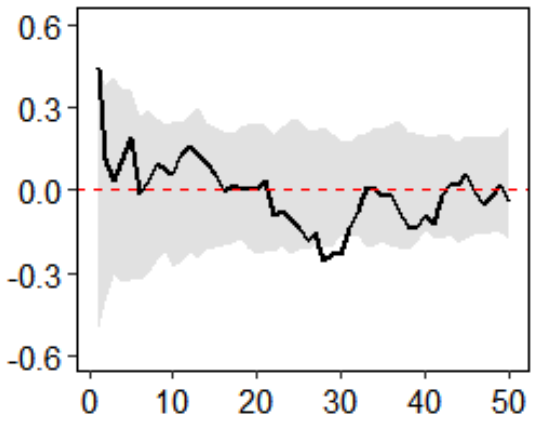

(d) Adults vs. subadults

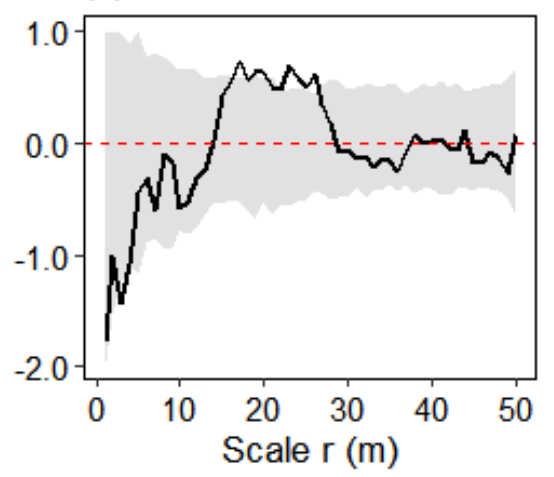

Figure 6. Test statistics $\mathrm{g}_{11}(\mathbf{r})-\mathrm{g}_{12}(\mathrm{r})$ and $\mathrm{g}_{21}(\mathrm{r})-\mathrm{g}_{22}(\mathrm{r})$ showing spatial associations between adult stage and two early stages in the life-history of Shorea roxburghii

According to the statistic test $g_{12}(r)-g_{11}(r)$ significant difference was found when comparing distributions of adult individuals of Shorea roxburghii and its juveniles (Fig. 6a) and its subadults (Fig. 6b). The statistic test $g_{12}(r)-g_{11}(r)<0$ indicates a higher density of adults trees than juveniles around it at a scales of 29-30 m (Fig. 6a), and a density of mature trees is higher than a subadults at a scales of $28-30 \mathrm{~m}$ (Fig. 6b).

Test statistic $g_{21}(r)-g_{22}(r)$ showed significant differences from the null model of random for juveniles (Fig. 6c) but not for subadults (Fig. 6d). This test shows that juveniles have an independent cluster distribution compared to adults trees at a distance of $0-5 \mathrm{~m}$. Results showed that there were strong additional clumping which were independent of adult individuals at earlier scales up to $5 \mathrm{~m}$ in the case of juveniles. For subadults, at scales $16 \mathrm{~m}, g_{21}(r)-g_{22}(r)>0$ meant that there were significantly less subadults surrounding adults compared with the adult-adult relationship (Fig. 6d).

\section{Heterospecific association of Shorea roxburghii}

The heterospecific association of Shorea roxburghii following its life stages is presented in Figure 7.

The juveniles individuals of Shorea roxburghii were independent of the heterospecific adults (Fig. 7a). However, the subadults of $S$. roxburghii were marginally repulsed by heterospecific adults at a scale of 27 to $28 \mathrm{~m}$ (Fig. 7b). Likewise, adults individuals were also attracted by heterospecific adults at a scale of 10-29 m (Fig. 7c). There is competition for different species at the scale of 0-5 $\mathrm{m}$. Thus, there is strong 
evidence of interspecific repulsion existing between subadults and adults of Shorea roxburghii and its neighbours.

(a) Remaining adults vs.

S. roxburghii juveniles

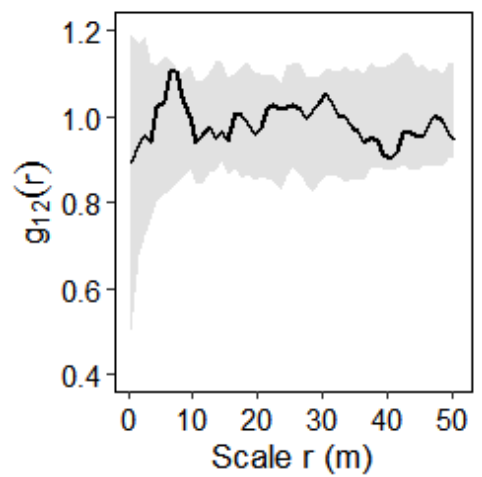

(b) Remaining adults vs.

S. roxburghii subadults

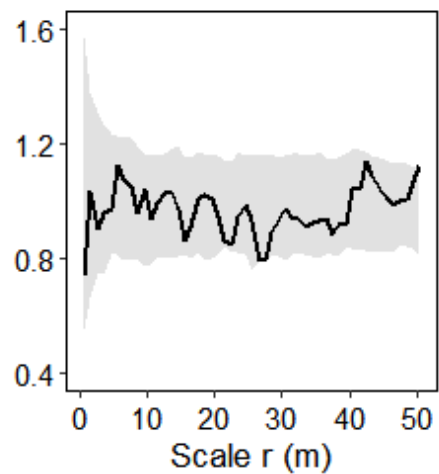

(c) Remaining adults vs.

S. roxburghii adults

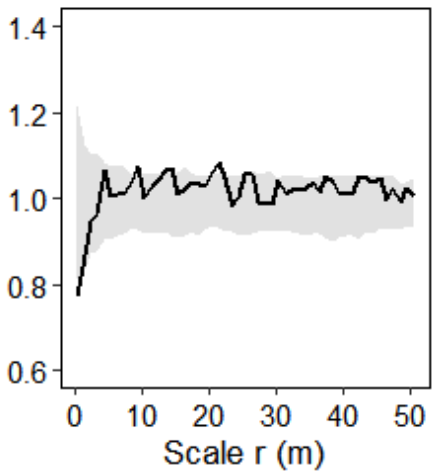

Figure 7. The bivariate pair-correlation functions show association patterns between adults of remaining species and different life stages of Shorea roxburghii

\section{Discussion}

\section{Dendrometric characteristics and diameter class distribution}

In the studied area, we found that the species Shorea roxburghii has the higher value of basal area, maximum dbh, important value index and lower median NN (nearest neighbour distance) when compared to four other dominant species (Aporosa planchoniana, Syzygium zeylanicum, Vatica odorata and Anisoptera costata). When it is compared to the remaining 106 species (except for four other dominant species), its maximum dbh value is very small. This can be explained by the fact that the species is threatened and logged as commercial timber and "white meranti" in many southern Asia countries where it is located including in South Vietnam (Pooma et al., 2017; Mun et al., 2018). Logically, when people exploit a species for timber of plank production, they mainly focus their attention on individuals with bigger diameter than smaller ones. This could also be an explanation of why the species does not have many representatives in high diameter classes above $50 \mathrm{~cm}$ of dbh (Fig. 2). As found by Dupuy (1998) in tropical Africa forests and by Hoang (2010) and Pham et al. (2020) in Vietnam evergreen forests, threatened species are usually represented by smaller trees (in terms of dbh) in forest stands where they occur. But also, the reverse J-shaped distribution size structure of $S$. roxburghii (presence of many individuals in lower diameter classes) can suggest continuous population regeneration and environmental suitability for establishment and survival of seedlings (Dupuy, 1998; Nguyen et al., 2014). Thus, in Dipterocarpaceae forests where $S$. roxburghii is a dominant tree species, the similarity coefficient of value between mature individuals and regenerating individuals is high, $96.4 \%$ for the study conducted by Long et al. (2018) in the Tan Phu area of Dong Nai Province in Vietnam.

\section{Spatial patterns of Shorea roxburghii}

In the light of Figure $4 a, b$ there exists strong competition within all adults individuals at scales $\leq 2 \mathrm{~m}$. When the aggregation of individuals is observed at scales smaller than $20 \mathrm{~m}$, it means that there is seed dispersal limitation or seed facilitation 
(Hubbell et al., 2001; Nguyen et al., 2014). At larger scales, this aggregation may be obscured by the environmental heterogeneity (Nguyen et al., 2014) because local environment plays an important role in the spatial distribution patterns of tree species (John et al., 2007). One of possible explanations for the aggregated patterns of most species is the effect of dispersal facilized by the ability of pioneer species to establish their seed in the forest stand as they are to the proximity of parent trees (Dalling et al., 2002; Fibich et al., 2016).

The different life-history stages of Shorea roxburghii do not have the same spatial distribution patterns (Fig. 5f-h). Its juveniles and subadults showed clustered spatial distribution patterns at lower scales (Fig. 5f, g) while its adults showed regular or clustered patterns. The adults individuals were overdispersed at $1 \mathrm{~m}$ scale and random between 1-50 $\mathrm{m}$ scale. These different spatial patterns in the life-history of the species suggest dynamic changes in its population and existence of self-thinning process resulting from competition for natural resources (Nguyen et al., 2014) and confirm the fact that habitat heterogeneity can cause individual aggregation (Wang et al., 2020). This can be explained by the species' light requirement at different stages (Nguyen et al., 2014; Cirimwami et al., 2017), its successional dynamics (Wédjangon et al., 2020), its crown spatial patterns (Blanchard et al., 2016) and the intensity of competition at each level of growth (Getzin et al., 2006; Guo et al., 2013). The density of Shorea roxburghii has a cluster distribution and decreases as the distance and age of the tree increases (dbh increases, from juveniles to subadults, adults) and changes to evenly distributed in adults trees. This is a clear sign of competition for nutrient space between plants and plants during growth.

The cluster pattern distribution of forest tree individuals at distances less than $20 \mathrm{~m}$ which is often interpreted as seed dispersal limitation or facilitation (Hubbell et al., 2001; Uriarte et al., 2004) while at larger scales, it may be obscured by environmental heterogeneity, e.g. rock outcrops, slope or soil nutrients (Harms et al., 2001; John et al., 2007). The test results of the univariate L-function and the pair-correlation function showed that the environmental heterogeneity played a big role in the structuration of the vegetation in the study plot. Environmental heterogeneity in the same study plot in tropical rainforest subject is a fairly common phenomenon, it has been proven in many previously published studies, with cumulative density of all adult trees changed from regularity or random distribution to cluster distribution at distances over $20 \mathrm{~m}$ (Wiegand et al., 2007).

In the spatial relationship between the life stages of forest trees, two important mechanisms, density-dependent mortality and gap-phase regeneration mode regulate the relationships of the life stages (Nguyen et al., 2014). Figure $6 a$ and $b$ also show that the density of subadults of $S$. roxburghii and juveniles around the adults is lower than that of the adult's trees around it, the juveniles and subadults are distributed around the adults with similar density. This may be due to the density-dependent mortality rate, in particular governed by natural thinning that resulted in a decrease in the density around the parent plant (Wright, 2002). In addition, juveniles have an independent cluster distribution from adults trees (larger diameter size). Another mechanism could be the gap-phase regeneration mode (Hamill and Wright, 1986; Condit et al., 1992), however, considering the ecological characteristics of the species, previous studies on regeneration of $S$. roxburghii can see that it is a shade tolerant plant, so when it is young it needs to live under the mother tree or larger trees. So there is no gap-phase regeneration. 


\section{Conclusion}

This study conducted in rich southern evergreen forests of Vietnam aimed the understanding of population structure and spatial distribution patterns of Shorea roxburghii. This species is a Dipterocarpaceae threatened species from south Asia, classified as "Vulnerable" on the IUCN red list.

In the broadleaf secondary forest in the study area, Shorea roxburghii is a shade tolerant tree species living in the lower layer. Its dbh size is small but densely populated, and with 4 dominant tree species, it can form the dominant tree species group. In terms of the IVI index, it accounts for the highest percentage, making it an important plant species in the stand. Shorea roxburghii has both regular patterns and a cluster pattern at small distances, but the general trend is to have cluster type distribution at a scale up to $25 \mathrm{~m}$, the density decreases as the distance increases. This species has a cluster type distribution in the juveniles tree and subadults tree stage, evenly distributed or clustered in the adults tree stage. However, the general trend is evenly distributed as the age of the trees increases. Shorea roxburghii juveniles were found to have a cluster distribution independent of mature trees at a distance less than $10 \mathrm{~m}$.

For this species (Shorea roxburghii), there is competition for different species and the same species at the scale of $0-5 \mathrm{~m}$ in adult stage. In the juveniles and subadults stage, the competition is not clear because the size of the small trees and the environment in the study plot is heterogeneous. Natural thinning and strong dispersal (winged fruit) are the mechanisms that govern the spatial distribution pattern of Shorea roxburghii species. In addition, the competition for the same species at the distance of 0-5 $\mathrm{m}$ of mature trees should be considered when planting pure forest with this tree to expand the area of distribution of tree species. These findings are key resource for the conservation of this species and the forests in which it occurs.

We recommend carrying out study to the influence of environmental factors (soil, altitude, topography, and climate) on the distribution characteristics of Shorea roxburghii species in future studies; on that basis the ecological information about this plant will be more complete.

Acknowledgement. The authors would like to thank Prof. Dr. Kang Yong Yong-Xiang, Dr. Nguyen Hong Hai, Dr. Nguyen Thanh Tuan, and the research team of Northwest A\&F University, China for their valuable assistance during the preparation of the manuscript.

\section{REFERENCES}

[1] Amani, I. A. C., Lejoly, J. (2014): Floristic patterns and impact of edaphic heterogeneity on species assemblages within woody forests layers in semi-deciduous forests from the Congo Basin. - Greener Journal of Agronomy, Forestry and Horticulture 2(3): 62.

[2] Arévalo, J. R., Fernández-Palacios, J. M. (2003): Spatial patterns of tree and juveniles in a laurel forest of Tenerife, Canary Islands. - Plant Ecology 165(1): 0.

[3] Baddeley, A., Rubak, E., Turner, R. (2015): Spatial Point Patterns: Methodology and Applications with R. - Chapman and Hall/CRC Press, London.

[4] Bivand, R. S., Pebesma, E. J., Gómez-Rubio, V. (2008): Applied Spatial Data Analysis with R. - Springer Science. Business Media, LLC, Berlin.

[5] Blanchard, E., Birnbaum, P., Ibanez, T., Boutreux, T., Antin, C., Ploton, P., Vincent, G., Pouteau, R., Vendroit, H., Hequet, V., Barbier, N., Droissart, V., Sonké, B., Texier, N., 
Kamdem, N. G., Zebaze, D., Libalah, M., Couteron, P. (2016): Contrasted allometries between stem diameter, crown area, and tree height in five tropical biogeographic areas. Trees 30: 195968.

[6] Bolibok, L. (2008): Limitations of Ripley's K(t) function use in the analysis of spatial patterns of tree stands with heterogeneous structure. - Acta Sci. Pol. Silv. Colendar. Rat. Ind. Lignar. 7(1).

[7] Brower, J. E., Jerold, H. Z., Von Ende, C. (1997): Field and Laboratory Methods for General Ecology. - McGraw-Hill Education, New York.

[8] Call, L. J., Nilsen, E. T. (2003): Analysis of spatial association between the invasive Tree-of-Heaven (Ailanthus altissima) and the Native Black Locust (Robinia pseudoacacia). - The American Midland Naturalist 1(150): 1-14.

[9] Cirimwami, L., Gourlet-Fleury, S., Gonmadje, C., Kahindo, J-M., Doumenge, C., Gonmadje, C., Amani, C. (2017): Does the altitude affect the stability of montane forests? A study in the Kahuzi-Biega National Park (Democratic Republic of the Congo). Applied Ecology and Environmental Research 15(4): 169713.

[10] Cirimwami, L., Kahindo, J-M., Doumenge, C., Amani, C. (2019): The effect of elevation on species richness in tropical forests depends on the considered lifeform: results from an East African mountain forest. - Tropical Ecology 60(4): 4784.

[11] Condit, R., Hubbell, S. P., Lafrankie, J. V., Sukumar, R., Manokaran, N., Foster, N. B., Ashton, P. S. (1996): Species-area and species-individual relationships for tropical trees: a comparison of three 50-ha plots. - Journal of Ecology 84(4): 549-562.

[12] Curtis, J. T., Macintosh, R. P. (1951): An upland forest continuum in the prairie - forest border region of Wisconsin. - Ecology 32(3): 4796.

[13] Dalling, J. W., Muller-Landau, H. C., Wright, S. J., Hubbell, S. P. (2002): Role of dispersal in the recruitment limitation of neotropical pioneer species. - Journal of Ecology 90(4): 714-727.

[14] Dixon, P. M. (2002): Ripley's K function. - Encyclopedia of Environmetrics 3: 17961803.

[15] Dupuy, B. (1998): Bases pour une sylviculture en forêt dense tropicale humide africaine. - Série FORAFRI Document 4, CIRAD-Forêt.

[16] Fibich, P., Lepš, J., Novotný, V., Klimeš, P., Těšitel, J., Molem, K., Damas, K., Weiblen, G. (2016): Spatial patterns of tree species distribution in New Guinea primary and secondary lowland rain forest. - Journal of Vegetation Sciences 27(2): 3239.

[17] Getzin, S., Dean, C., He, F., Trofymow, J. A., Wiegand, K., Wiegand, T. (2006): Spatial patterns and competition of tree species in a Douglas-fir chronosequence on Vancouver Island. - Ecography 29(5): 6782.

[18] Getzin, S., Wiegand, T., Wiegand, K., He, F. (2008): Heterogeneity influences spatial patterns and demographics in forest stands. - Journal of Ecology 96: 8020.

[19] Guo, Y., Lu, J., Franklin, S. B., Wang, Q., Xu, Y., Zhang, K., Bao, D., Qiao, X., Huang, H., Lu, Z., Jiang, M. (2013): Spatial distribution of tree species in a species-rich subtropical mountain forest in Central China. - Can. J. For. Res. 43(9): 8235.

[20] Hamil, D. N., Wright, S. J. (1986): Testing the dispersion of juveniles relative to adults: a new analytic method. - Ecology 67(4): 9557.

[21] Harms, E. K., Condit, R., Hubbell, S. P., Foster, R. B. (2001): Habitat associations of trees and shrubs in a 50-ha neotropical forest plot. - Journal of Ecology 89: 9459.

[22] Hoang, V. H. (2010): Evaluation of the Conservation Status and Risks for Some Endangered Plant Species in Ba Be National Park, Backan Province, Vietnam. University of Technology, Sydney.

[23] Hubbell, S. P. (2001): The Unified Neutral Theory of Biodiversity and Biogeography. Princeton University Press, United Kingdom.

[24] Illian, J., Penttinen, A., Stoyan, H., Stoyan, D. (2008): Statistical Analysis and Modelling of Spatial Point Patterns. - John Wiley and Sons, Chichester. 
[25] John, R., Dalling, J. W., Harms, K. E., Yavitt, J. B., Stallard, R. F., Mirabello, M., Hubbell, S. P., Valencia, R., Navarrete, H., Vallejo, M., Foster, R. (2007): Soil nutrients influence spatial distributions of tropical tree species. - PNAS 104(3): 8669.

[26] Long, L. V., Tuyen, P. T., Toan, L. B., Quy, P. X. (2018): Natural regeneration characteristics of tropical evergreen moist close forest in Tan Phu area of Dong Nai Province. - Journal of Forestry Sciences and Technology 5(11): 32.

[27] Marcon, E. (2010): Statistiques spatiales avec applications à l'écologie et à l'économie. Biodiversité et Ecologie. Ph.D. Thesis, AgroParisTech, Paris.

[28] Mun, H. W. (2018): Assessment of growth and biomass of Shorea roxburghii G. Don in selected areas of peninsular Malaysia. - International Journal of Agriculture, Forestry and Plantation 7: 45.

[29] Nguyen, H. H. (2017): Methods of spatial point pattern analysis applied in forest ecology. - National Scientific Conference on Ecology and Biological Resources 7: 160617.

[30] Nguyen, H., Wiegand, K., Getzin, S. (2014): Spatial patterns and demographics of Streblus macrophyllus in a tropical evergreen forest, Vietnam. - Journal of Tropical Forest Science 26(3): 3019.

[31] Nguyen, H. H., Erfanifard, Y., Bao, T. Q., Petritan, A. M., Mai, T. H., Petritan, I. C. (2020a): Phylogenetic community and rearest neighbor structure of disturbed tropical rain forests encroached by Streblus macrophyllus. - Forests 11(7): 722.

[32] Nguyen, V. H., Le Hong, V., Tran, Q. B., Nguyen, T. L. (2020b): Woody plant diversity and aboveground carbon stocks of (Shorea roxburghii) dominant forests in Tan Phu, Dong Nai province. - Journal of Forestry Science and Technology 10: 66-76.

[33] Nguyen, T. T., Tran, T. C., Tran, Q. B. (2020c): Individual tree diameter increment and mortality models for medium and rich forest in Dong Nai Culture and Nature Reserve. Vietnam Journal of Forest Science 3: 73-86.

[34] Nguyen, H. H., Erfanifard, Y., Bui, V. B., Mai, T. H., Petritan, A. M., Petritan, I. C. (2021): Topographic effects on the spatial species associations in diverse heterogeneous tropical evergreen forests. - Sustainability 13(5): 2468.

[35] Pham, V. V., Ammer, C., Annighöfer, P. (2020): The presence of IUCN Red list tree species in dependence of site characteristics in the Vietnamese Cat Ba National Park. Sustanability12(3): 104.

[36] Pooma, R., Newman, M., Barstow, M. (2017): Shorea roxburghii. - The IUCN Red List of Threatened Species 2017.

[37] Raju, A. J. S., Ramana, K. V., Jonathan, K. H. (2009): Anemophily, anemochory, seed predation and seedling ecology of Shorea tumbuggaia Roxb. (Dipterocarpaceae), an endemic and globally endangered red listed semi-evergreen tree species. - Current Science 96(6): 827-833.

[38] Raju, A. J. S., Ramana, K. V., Chandra, P. H. (2011): Reproductive ecology of Shorea roxburghii G. Don (Dipterocarpaceae), an endangered semievergreen tree species of peninsular India. - Journal of Threatened Taxa 3(9): 206070.

[39] Ripley, B. D. (1976): The second-order analysis of stationary point processes. - Journal of Applied Probability 13(2): 255-266.

[40] Sotirios, K., Alan, B. G. (2005): Spatial relationships between tree species and gap characteristics in broad-leaved deciduous woodland. - Journal of Vegetation Science 16(5): 5896.

[41] Szmyt, J. (2014): Spatial statistics in ecological analysis: from indices to functions. Silva Fennica 48(1): 31.

[42] Uriarte, M., Condit, R., Canham, C. D., Hubbell. S. P. (2004): A spatially explicit model of sapling growth in a tropical forest: does the identity of neighbours matter? - Journal of Ecology 92(2): 3460.

[43] Wang, X., Jiang, C., Jia, C., Tai, Y., Hou, Y., Zhang, W. (2020): A new digital method of data collection for spatial point pattern analysis in grassland communities. - Ecology and Evolution 10(14): 785860. 
[44] Wédjangon, A. A., Kuiga, N. B. S., Houêtchétgnon, T., Ouinsavi, C. A. I. N. (2020): Spatial ditribution and interspecific association patterns between Mansonia altissima A. Chev., Ceiba pentandra (L.) Gaertn and Triplochiton scleroxylon K. Schum. in a moist semi-deciduous forest. - Annals of Forest Sciences 77(1): 6.

[45] Wiegand, T., Moloney, K. A. (2004): Rings, circles, and null models for point pattern analysis in ecology. - Oikos 104(2): 2029.

[46] Wiegand, T., Gunatilleke, C. V. S., Gunatilleke, I. A. U. N. (2007): Species associations in a heterogeneous Sri Lankan dipterocarp forest. - The American Naturalist 170(4): 75.

[47] Wright, S. J. (2002): Plant diversity in tropical forests: a review of mechanisms of species coexistence. - Oecologia 130(1): 1-14. 